\title{
Using the Learning Management System "Modular Object-Oriented Dynamic Learning Environment" in Multilingual Education
}

\author{
https://doi.org/10.3991/ijet.v17i03.25851 \\ Si Qin ${ }^{1}$, Larisa Orchakova ${ }^{2}, \mathrm{Zi}_{-} \mathrm{Yu} \mathrm{Liu}^{3}\left({ }^{凶}\right)$, Yulia Smirnova ${ }^{4}$, Elena Tokareva ${ }^{4}$ \\ ${ }^{1}$ HuBei University of Economics, Hubei, China \\ ${ }^{2}$ Moscow City University, Moscow, Russia \\ ${ }^{3}$ GuangXi Normal University, Guilin, China \\ ${ }^{4}$ Moscow City University, Moscow, Russian Federation \\ 51995812@qq. com
}

\begin{abstract}
The article aims to study the possibilities, identify features, and assess the prospects for using the LMS MOODLE system (learning management system "Modular Object-Oriented Dynamic Learning Environment") for the formation of language skills in multilingual education. The study involved two groups of respondents, comparable in gender and age: 112 linguistic students (group A) and 109 non-linguistic students studying several foreign languages (group B). The respondents' answers to the questions of a specially developed questionnaire were analyzed, which made it possible to compare the parameters of training using the LMS MOODLE platform and traditional classroom training. To determine the connotative (individual-value) attitude towards obtaining multilingual education using the LMS MOODLE platform and to identify its subjective-personal meaning, Ch. Osgood's semantic differential method was used on the basis of a seven-point bipolar scale. Linguistic and non-linguistic students assessed differently LMS MOODLE platform for multilingual education, which is associated with different motives for acquiring multilingual competence and its professional significance.
\end{abstract}

Keywords—distance learning, LMS MOODLE, multilingual learning, online educational platforms, semantic differential method

\section{Introduction}

Today, an important task of the educational process is to increase students' motivation and develop their critical thinking skills and professional language competence [1]. This is especially relevant in the active introduction of online education. It should be emphasized that for many areas, distance learning has begun to be used only in connection with the COVID-19 pandemic; however, it was used even in the precomputer era in the form of written assignments, television, and audio lessons. It is relevant to study the possibilities of various online learning platforms for students' 
language skills formation. LMS MOODLE is widely used in many countries; therefore, the study of its effectiveness for multilingual education is of interest.

The research object is multilingual education; the research subject is the possibilities and prospects of using LMS MOODLE for multilingual education. Accordingly, the research purpose is to study the possibilities, identify features, and assess the prospects for using LMS MOODLE for language skills formation in multilingual education.

The main study objectives are to determine the effectiveness of using LMS MOODLE for language skills formation in multilingual education compared to traditional education forms on the example of linguistic and non-linguistic universities in China and Russia.

The study hypothesis is the assumption that LMS MOODLE is an effective platform for the formation of students' language skills in multilingual learning.

\section{Literature review}

LMS MOODLE is a global, convenient, and free online learning management system based on the principles of interactivity and creativity [2-4]. It is an easy-to-learn and easy-to-use platform designed to provide educators, administrators, and students with a single, reliable, secure, and integrated system to create personalized environments that enhance both teaching and learning $[3,5,6]$. The introduction and active distribution of LMS MOODLE have begun in 2002, and since then it has become the most widely used training platform, which has 213 million users; besides, LMS MOODLE partner network includes more than 40 companies around the world [6,7]. One of the advantages of LMS MOODLE is adherence to a competency-based approach, which allows one to create an individual course [2,8]. An important parameter of LMS MOODLE is multilingual capabilities, which not only guarantee the absence of language restrictions for online learning but also provide conditions for multilingual education [9,10]. Multilingual competence in the modern world is necessary for specialists in any field of activity; therefore, mastering foreign languages is important $[11,12]$.

Multilingual education contributes to the formation of personal, intellectual, sociocultural competencies that contribute to effective communication with carriers of other cultures and provide social and professional mobility in the global labor market $[12,13]$. Multilingual education is aimed at preserving and supporting linguistic and cultural diversity and the formation of multilingual individuals through various education models. Language studies are integrated with humanities and science subjects [14-17]. Multilingual education is understood today as a unified system of teaching foreign languages for multilingual communication [17-19] based on linguistic, cognitive, sociocultural, and pragmatic experience [13]. This definition reflects the idea of multilingual education. Based on psycholinguistic data, new knowledge remains in memory only if it is integrated into the existing system of knowledge [20,21]. Due to globalization and internationalization, European countries make multilingual educa- 
tion a language policy of the European Union, determining its relevance for the formation of functional multilingualism [20,21].

The implementation of multilingual education principles is associated with the need to create a unified system of teaching foreign languages, in which a native language is the basis for the study of several foreign languages and the formation of general linguistic competence. This approach presupposes the presence of coordinated curricula, as well as the creation of teaching aids for linguistic and non-linguistic universities. Therefore, teaching based on a multilingual methodology in modern universities requires an appropriate level of linguistic, scientific, and methodological skills of foreign language teachers [20,21]. LMS MOODLE can be considered an important tool in multilingual education in modern universities [20-22]. Educators and students today are faced with a variety of e-learning software applications [23]. One of the main principles of work consistency within the multilingual methodology is educational process optimization in temporal, cognitive, linguo-methodological, and other aspects. It is also important to create comparative textbooks that ensure the use of two or more languages in the educational process simultaneously [20,21].

Optimization can be achieved by using the capabilities of LMS MOODLE, which allows one to create the prerequisites for the implementation of multilingual learning tasks $[20,21]$. The process of introducing multilingual education in both linguistic and non-linguistic universities requires the creation of necessary conditions and prerequisites for working with this methodology [20,21]. This presupposes the unified concept of teaching and unified approaches to determining the typology of tasks, activities, functions, and methods of control based on linguistic universals [20,21]. In this aspect, LMS MOODLE platform creates a multilingual educational space that integrates multiple languages in educational and research activities, contributing to a person's multilingualism in the process of continuous language learning [13,24].

LMS MOODLE is an innovative technology that provides an integrative approach to solving scientific and educational problems, strengthens the position of national languages, and allows training competitive specialists. An important advantage of LMS MOODLE is the ability to adapt the teaching process to the needs of students with disabilities [25], which corresponds to the modern tasks of creating a barrier-free educational space. Distance learning technologies, such as LMS MOODLE, are convenient to use for transmitting information, organizing interactive classes, and for current and intermediate control. The process of multilingual education is aimed at the formation of multilingual communicative competence in students, consisting of motivational, communicative, and emotional-volitional components [6,26-28]. Multilingual education technologies are aimed at developing intellectual and personal qualities of students, intensifying general and additional foreign language education, helping to improve the quality level of professional training, and instilling interest in international communication. Such technologies allow one to manage the process of multilingual education, as well as effectively use additional resources for selfimprovement. Thus, the development of multilingual technologies is a promising area that provides training for specialists in modern conditions of the global labor market $[21,26,27,29,30]$. 
The concept and methodology for the development of students' foreign language competence are based on enhancing their independence [22], which is directly related to the use of online technologies. The implementation of multilingual education courses on LMS MOODLE platform allows one to observe the principle of a competency-based approach, as well as to build an individual learning mode [31] for each student. This approach is aimed at achieving progress in learning; it does not stigmatize a student and allows him/her to develop potential. The knowledge-based approach increases students' motivation, while the competency-based approach satisfies the need for more practical learning, which contributes to greater student autonomy and subsequent more effective employment [23]. The dynamism of the competence training of each student within a limited time in a static environment is provided by a virtual teaching platform, among the advantages of which are students' ability to track their learning, personal courses, joint learning, and synchronous events (video conferences, chats, forums). E-learning systems allow one to accumulate a large amount of information and analyze possible errors or shortcomings [23]. In this regard, LMS MOODLE, as an interactive learning platform, is characterized by ease of use, an intuitive interface, a large number of proposed functions, as well as additional resources that extend the functionality of the system. Therefore, the number of educational institutions offering distance learning on LMS MOODLE platform is constantly growing [2].

LMS MOODLE organizes interaction between teachers and students, creating an online learning environment with the provision of educational or communication courses [2]. LMS MOODLE has several tools: chat, forum, task, quiz, etc. These multimedia tools allow interactive activities, thereby increasing students' interest and motivation to learn. Unlike traditional classroom activities, LMS MOODLE allows for diversification of classes and resources and facilitates real-time interaction between students and teachers [2]. Long-term digital technologies promote personalized learning and intercultural communication, developing students' deeper understanding of the influence of culture on behavior and thinking [32]. Using digital technologies, students can create digital profiles, post comments, ask questions, exchange information, thus acquiring the linguistic and cultural experience in a virtual space. In this context, the platform is an effective means of digital technologies' integration into multilingual education, expanding learning opportunities [32]. Mobile Internet technologies open up new possibilities for using blended learning by combining different learning forms and integrating different ways of accessing content [33]. The problem of teaching a foreign language in a globalizing world is associated with the inclusion of cognitive linguo-cultural aspects and a competency-based approach in the formation of intercultural communicative competence [34]. The use of digital technologies in education promotes active and effective learning, allowing one to gain a realistic experience [35].

The possibilities of LMS MOODLE tools make it possible to implement a university's innovative policy by creating a high-quality information and communication environment that corresponds to the current trends in science and technology, world education standards, and the needs of the information society [4]. LMS MOODLE provides a comprehensive educational process through extensive educational content, 
control systems, monitoring, and assessment of knowledge quality. Today it is almost impossible to implement the educational process without the use of information and communication technologies (ICTs), especially in higher education. Online learning enhances thinking and innovative skills in students [36]. LMS MOODLE allows one not only to store information but also to provide a quick and accurate analysis of learning statistics so that it can be used to predict student success, identify those who have difficulties in completing the course, and stimulate better results during training [37], making higher education more flexible [31,38]. Using the MOODLE platform helps to make education more accessible and convenient, to improve student performance [3]. In general, the advantages of distance platforms are greater freedom of access, lower tuition fees, the possibility of dividing the content of an e-course into modules, flexibility of learning, the ability to keep up with the modern pace of life, and the ability to define criteria for assessing knowledge, which justifies the need for their widespread implementation [3].

Thus, the scientific literature sources have enough information about the LMS MOODLE and its use for multilingual education. At the same time, the differentiated features of this system's application for multilingual education in linguistic and nonlinguistic universities have not been disclosed, which is of interest and therefore is considered in this article.

\section{$3 \quad$ Method}

\subsection{The study design}

The study design assumed the consistent implementation of the set goals and objectives in several stages:

- conducting an analytical review of the literature on distance multilingual education and the use of LMS MOODLE for this purpose;

- selection of valid research methods: preparing a questionnaire to assess the use by linguistic and non-linguistic students of LMS MOODLE; semantic differential method;

- formation of a randomized sample of respondents;

- research and statistical processing of the results;

- formulation of conclusions and practical recommendations.

\subsection{Research methods}

The selection of respondents to participate in the study was carried out by randomization, which ensured the impossibility of biased distribution. Groups of respondents matched by gender and age were randomly selected from students of 4 language universities (group A) and 4 non-language universities studying several foreign languages (group B) in Russia and China. Selection of a random sample was based on the National Standard of the Russian Federation "Statistical Methods" (GOST R ISO 
24153-2012), which is identical to the international standard (ISO 24153:2009 Random sampling and randomization procedures). 30 students from each university were selected to participate in the study, to whom the questionnaires were sent online. However, not all of the questionnaires turned out to be relevant (not all of the questions were answered, 5 questionnaires were not submitted). As a result, the first group (A) included 112 language students, the second (B) - 109 non-language students studying several foreign languages (Table 1). The groups of respondents were comparable in terms of gender and age. It should also be noted that Russian language is the native language for Russian students; they studied English, Chinese, and Japanese as foreign languages. For Chinese students, foreign languages were Russian, English, and Japanese. The study was conducted in 2000; all students were of 3rd year of study (6th semester).

Table 1. Characteristics of respondent groups

\begin{tabular}{|c|c|c|c|c|c|}
\hline \multirow{2}{*}{\multicolumn{2}{|c|}{ Parameters }} & \multicolumn{2}{|c|}{$\mathbf{A}$} & \multicolumn{2}{|c|}{ B } \\
\hline & & \multirow{2}{*}{$\begin{array}{l}\boldsymbol{N} \\
58\end{array}$} & \multirow{2}{*}{$\begin{array}{c}\% \\
51.8\end{array}$} & \multirow{2}{*}{\begin{tabular}{|c|}
$n$ \\
53
\end{tabular}} & \multirow{2}{*}{$\begin{array}{c}\% \\
48.6\end{array}$} \\
\hline & Russia & & & & \\
\hline evantiy & China & 54 & 48.2 & 56 & 51.3 \\
\hline \multirow{2}{*}{ Gender } & M & 69 & 61.6 & 67 & 61.5 \\
\hline & $\mathrm{F}$ & 43 & 38.4 & 42 & 38.5 \\
\hline \multirow{3}{*}{ Age } & $20-24$ & 21 & 18.8 & 16 & 14.7 \\
\hline & $25-29$ & 56 & 50.0 & 52 & 47.7 \\
\hline & $30-34$ & 35 & 31.2 & 41 & 37.6 \\
\hline Total & & 112 & 100 & 109 & 100 \\
\hline
\end{tabular}

A specially designed questionnaire was used to compare the parameters of training using LMS MOODLE platform and traditional classroom training. To determine the connotative (individual-value) attitude towards obtaining multilingual education using LMS MOODLE platform and to identify its subjective-personal meaning, Ch. Osgood's semantic differential scale was used with a seven-point bipolar scale [4,39,40]. These scales were used to verbalize the response to the multilingual learning using LMS MOODLE platform and provide an opportunity to compare the respondents' assessments. At the same time, 0 meant neutral attitude, 1 - low, 2 - average, 3 - high (with a "+" or "-"). Further, a factor analysis of the results obtained was carried out according to three factors: assessments (good-bad), strength (effective-ineffective), and activity (active-passive). The scales were adequate to the research objectives and presented in random order; the left pole did not correspond to a negative quality and the right one did not correspond to a positive one. The degree of similarity or difference in respondents' profiles was calculated using the formula (medstatistic.ru):

$$
D(x, y)=\sqrt{\sum d}(x i, y i)^{2}
$$

where $\mathrm{D}(\mathrm{x}, \mathrm{y})$ - semantic distance between objects $\mathrm{x}$ and $\mathrm{y}$ (i.e., respondents' estimates); xi, yi - the difference between the coordinates of two points that represent the values of objects $\mathrm{X}$ and $\mathrm{Y}$ by factor, which made it possible to objectify subjective 
respondents' assessments of the multilingual education using LMS MOODLE platform. To measure the stereotypical differential (highlighting the stereotypical characteristics of the LMS MOODLE process under study), the polarity of the characteristics was determined using the Student's t-test formula (medstatistic.ru):

$$
t=(M-\mu) / S \sqrt{n}
$$

where $\mathrm{n}$ - number of respondents participating in the study; $\mathrm{M}$ - scale mean; $\mu$ scale neutral $(\mu=4$, if a 7-point scale is used, as in the present study); S - standard deviation on the corresponding scale.

Statistical processing of the research results was carried out using an online calculator medstatistic.ru. To compare the quantitative indicator in the two groups in the absence of a normal distribution, the Mann-Whitney test was used.

\subsection{Ethical issues}

The anonymity of respondents in the research process was ensured through compliance with the principle of informed consent and special coding of online questionnaires without indicating the personal data of research participants in the questionnaires.

In the study, there was no conflict of interest and no additional funding was allocated.

\section{$4 \quad$ Results}

Based on the analysis of literature on various aspects of LMS MOODLE platform, a special questionnaire was developed that covered various aspects that allow one to assess the effectiveness of this platform for multilingual education. First of all, this concerned the study of LMS MOODLE's influence on the formation of motivational, communicative, and emotional-volitional components of multilingual communicative competence in students by creating a high-quality information and communication environment. It was relevant to analyze the effect of LMS MOODLE platform on foreign language learning and the level of academic performance in multilingual education according to students' subjective assessment (Table 2). The concept of multilingual education involves teaching several foreign languages based on the already existing knowledge of a foreign or native language. In this study, language students differed in prior knowledge of foreign languages, while simultaneously studying two or more new languages. Non-linguistic students, as a rule, mastered two new languages (98.2\%), while $24.8 \%$ of them did not have basic foreign language training. 
Paper_-Using the Learning Management System "Modular Object-Oriented Dynamic Learning...

Table 2. Results of linguistic and non-linguistic students' subjective assessment of LMS MOODLE use in multilingual education

\begin{tabular}{|c|c|c|c|c|c|c|c|}
\hline \multirow{2}{*}{ No. } & \multirow{2}{*}{ Survey question } & \multicolumn{2}{|l|}{$\mathbf{A}$} & \multicolumn{2}{|l|}{$\mathbf{B}$} & \multirow{2}{*}{ Student's t-test } & \multirow{2}{*}{$\mathbf{p}$} \\
\hline & & absolute value & $\%$ & absolute value & $\%$ & & \\
\hline 1. & \multicolumn{7}{|c|}{ Do you speak any foreign language(s)? } \\
\hline A & Yes & 112 & 100 & 82 & 75.2 & 175.36 & $<0.05$ \\
\hline B & No & 0 & 0 & 27 & 24.8 & 175.36 & $<0.05$ \\
\hline 2. & \multicolumn{7}{|c|}{ How many foreign languages are you currently studying? } \\
\hline A & Two & 89 & 79.5 & 107 & 98.2 & 132.23 & $<0.05$ \\
\hline B & Three & 18 & 16.1 & 2 & 1.8 & 101.12 & $<0.05$ \\
\hline $\mathrm{C}$ & four or more & 5 & 4.4 & 0 & 0 & 31.11 & $<0.05$ \\
\hline 3. & \multicolumn{7}{|c|}{ In what form does the training take place? } \\
\hline A & $\begin{array}{c}\text { in the classroom (tradi- } \\
\text { tional form) }\end{array}$ & 0 & 0 & 0 & 0 & 0 & - \\
\hline B & Online & 54 & 48.2 & 31 & 28.4 & 140.01 & $<0.05$ \\
\hline $\mathrm{C}$ & mixed form & 58 & 51.8 & 78 & 71.6 & 140.01 & $<0.05$ \\
\hline 4. & \multicolumn{7}{|c|}{ You are actively using LMS MOODLE platform for... } \\
\hline A & 1 semester & 34 & 30.4 & 46 & 42.2 & 83.44 & $<0.05$ \\
\hline $\mathrm{B}$ & 2 semesters & 60 & 53.5 & 56 & 51.4 & 14.85 & $<0.05$ \\
\hline $\mathrm{C}$ & 2 years or more & 18 & 16.1 & 7 & 6.4 & 68.59 & $<0.05$ \\
\hline 5. & \multicolumn{7}{|c|}{ How does LMS MOODLE affect communication with teachers? } \\
\hline A & Improves & 73 & 65.2 & 64 & 58.7 & 45.96 & $<0.05$ \\
\hline B & $\begin{array}{l}\text { does not affect in any } \\
\text { way }\end{array}$ & 24 & 21.4 & 32 & 29.4 & 56.57 & $<0.05$ \\
\hline $\mathrm{C}$ & Worsens & 15 & 13.4 & 13 & 11.9 & 10.61 & $<0.05$ \\
\hline 6. & \multicolumn{7}{|c|}{ How does LMS MOODLE affect communication with fellow students? } \\
\hline A & Improves & 41 & 36.6 & 37 & 33.9 & 19.09 & $<0.05$ \\
\hline B & $\begin{array}{l}\text { does not affect in any } \\
\text { way }\end{array}$ & 46 & 41.1 & 19 & 17.4 & 167.58 & $<0.05$ \\
\hline $\mathrm{C}$ & Worsens & 25 & 22.3 & 53 & 48.6 & 185.97 & $<0.05$ \\
\hline 7. & \multicolumn{7}{|c|}{ How does LMS MOODLE affect your interest in learning? } \\
\hline A & Enhances & 64 & 57.1 & 59 & 54.1 & 21.21 & $<0.05$ \\
\hline B & $\begin{array}{c}\text { does not affect in any } \\
\text { way }\end{array}$ & 31 & 27.7 & 34 & 31.2 & 24.75 & $<0.05$ \\
\hline $\mathrm{C}$ & Lowers & 17 & 15.2 & 16 & 14.7 & 3.54 & $<0.05$ \\
\hline 8. & \multicolumn{7}{|c|}{ Does the use of LMS MOODLE increase the motivation for multilingual learning? } \\
\hline A & Yes & 78 & 69.6 & 84 & 77.1 & 53.03 & $<0.05$ \\
\hline $\mathrm{B}$ & No & 34 & 30.4 & 25 & 22.9 & 53.03 & $<0.05$ \\
\hline 9. & \multicolumn{7}{|c|}{ Is it convenient to use LMS MOODLE for multilingual education? } \\
\hline A & Yes & 87 & 77.7 & 81 & 74.3 & 24.04 & $<0.05$ \\
\hline B & No & 25 & 22.3 & 28 & 25.7 & 24.04 & $<0.05$ \\
\hline 9. & \multicolumn{7}{|c|}{ Is the use of LMS MOODLE effective for multilingual education? } \\
\hline A & Yes & 93 & 83.0 & 85 & 78.0 & 35.36 & $<0.05$ \\
\hline $\mathrm{B}$ & No & 19 & 17.0 & 24 & 22.0 & 35.36 & $<0.05$ \\
\hline
\end{tabular}


Paper-Using the Learning Management System "Modular Object-Oriented Dynamic Learning...

\begin{tabular}{|c|c|c|c|c|c|c|c|}
\hline 10. & \multicolumn{7}{|c|}{ Has LMS MOODLE positively influenced your knowledge of foreign languages? } \\
\hline A & Yes & 88 & 78.6 & 77 & 70.6 & 56.57 & $<0.05$ \\
\hline B & No & 34 & 30.4 & 32 & 29.4 & 7.07 & $<0.05$ \\
\hline 11. & \multicolumn{7}{|c|}{ Using LMS MOODLE, your academic performance... } \\
\hline A & Increased & 79 & 70.5 & 86 & 78.9 & 59.40 & $<0.05$ \\
\hline B & has not changed & 25 & 22.3 & 12 & 11.0 & 79.90 & $<0.05$ \\
\hline $\mathrm{C}$ & Dropped & 8 & 7.1 & 11 & 10.1 & 21.21 & $<0.05$ \\
\hline 12. & \multicolumn{7}{|c|}{ Does work in LMS MOODLE develop students' independent work skills? } \\
\hline A & Yes & 98 & 87.5 & 92 & 84.4 & 21.92 & $<0.05$ \\
\hline B & No & 10 & 8.9 & 12 & 11.0 & 14.85 & $<0.05$ \\
\hline $\mathrm{C}$ & difficult to answer & 4 & 3.6 & 5 & 4.6 & 7.07 & $<0.05$ \\
\hline
\end{tabular}

\begin{tabular}{|c|c|c|c|c|c|c|c|}
\hline 13. & \multicolumn{7}{|c|}{$\begin{array}{l}\text { Does LMS MOODLE platform provide more advantages for multilingual education than traditional } \\
\text { classroom teaching? }\end{array}$} \\
\hline A & Yes & 95 & 84.8 & 83 & 76.1 & 61.52 & $<0.05$ \\
\hline B & No & 17 & 15.2 & 26 & 23.9 & 61.52 & $<0.05$ \\
\hline
\end{tabular}

\begin{tabular}{|c|c|c|c|c|c|c|c|}
\hline 14. & \multicolumn{7}{|c|}{ Problems in using LMS MOODLE are associated with... } \\
\hline A & Internet access & 34 & 30.5 & 27 & 24.8 & 40.31 & $<0.05$ \\
\hline & The quality of technical & & & & & & \\
\hline
\end{tabular}

\begin{tabular}{|c|c|c|c|c|c|c|c|}
\hline B & $\begin{array}{c}\text { The quality of technical } \\
\text { support }\end{array}$ & 22 & 19.6 & 25 & 22.9 & 23.33 & $<0.05$ \\
\hline C & $\begin{array}{c}\text { Insufficient readiness of } \\
\text { teachers to use ICTs }\end{array}$ & 18 & 16.1 & 24 & 22.0 & 41.72 & $<0.05$ \\
\hline D & $\begin{array}{l}\text { Insufficient independ- } \\
\text { ent work skills of } \\
\text { students }\end{array}$ & 51 & 45.5 & 49 & 45.0 & 3.54 & $<0.05$ \\
\hline E & $\begin{array}{c}\text { Students' and teachers' } \\
\text { insufficient mastery of } \\
\text { the system's capabili- } \\
\text { ties }\end{array}$ & 16 & 14.3 & 19 & 17.4 & 21.92 & $<0.05$ \\
\hline $\mathrm{F}$ & $\begin{array}{c}\text { Formal platform use } \\
\text { only (lack of feedback } \\
\text { or creative assignments, } \\
\text { etc.) }\end{array}$ & 38 & 33.9 & 44 & 40.4 & 45.96 & $<0.05$ \\
\hline 15. & \multicolumn{7}{|c|}{ Evaluate the results and prospects of using LMS MOODLE in multilingual education } \\
\hline A & very good & 28 & 25.0 & 26 & 23.9 & 7.78 & $<0.05$ \\
\hline B & Good & 59 & 52.7 & 63 & 57.8 & 36.06 & $<0.05$ \\
\hline $\mathrm{C}$ & Average & 25 & 22.3 & 17 & 15.6 & 47.38 & $<0.05$ \\
\hline $\mathrm{D}$ & $\mathrm{Bad}$ & 0 & 0 & 3 & 2.8 & 19.8 & $<0.05$ \\
\hline $\mathrm{E}$ & very bad & 0 & 0 & 0 & 0 & 0 & - \\
\hline \multicolumn{2}{|c|}{ Total } & 112 & 100 & 109 & 100 & & \\
\hline
\end{tabular}

All respondents studied either only remotely (on LMS MOODLE) or online training (on LMS MOODLE) was combined with traditional classroom work (blended learning). However, the experience of using this platform among non-linguistic students was limited mainly to $1-2$ semesters, while $16.1 \%$ of language students used LMS MOODLE for 2 or more years. 
To objectify the subjective assessment of the multilingual education using LMS MOODLE, the semantic differential method was used with 30 polar items reflecting 3 factors evaluated on a 7-point scale, the results of which are presented in Table 3, and Table 4 shows the results of factor analysis [4,39,40]. Factor 1 (assessment factor) reflected the emotional attitude of students to the process of multilingual education using LMS MOODLE (items: positive/negative, relevant/irrelevant, opti$\mathrm{mism} /$ pessimism, real/unreal, easy/difficult, important/insignificant, reasonable/farfetched, professional/unprofessional, proactive/childish, comfortable/uncomfortable). Factor 2 (power factor) reflected students' attitude to the process under study in relation to university's policy (items: modern/non-modern, democratic/authoritarian, leadership/subordination, decisive/dependent, help/intervention, stability/randomness, transparency/secrecy, openness/closedness, danger/safety, obvious/unreasonable). Factor 3 (activity factor) revealed respondents' willingness to innovative development and self-improvement (communicative/restrained, creative/standard, material/idea, definite/indefinite, expected/unexpected, flexible/routine, motivated/demotivated, innovative/conservative, initiative/passive, clarity/ambiguity).

Table 3. Assessment of LMS MOODLE in multilingual education using a semantic differential scale

\begin{tabular}{|c|c|c|}
\hline Positive & 1 & negative \\
\hline Relevant & & irrelevant \\
\hline Pessimism & & optimism \\
\hline Real & & unreal \\
\hline Difficult & & easy \\
\hline Insignificant & & important \\
\hline Reasonable & & far-fetched \\
\hline Unprofessional & & professional \\
\hline Comfortable & 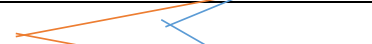 & uncomfortable \\
\hline Childish & & proactive \\
\hline Authoritarian & & democratic \\
\hline Modern & & non-modern \\
\hline Subordination & & leadership \\
\hline Dependent & $y$ & decisive \\
\hline Help & & intervention \\
\hline Randomness & & stability \\
\hline Transparency & & secrecy \\
\hline Closedness & & openness \\
\hline Danger & 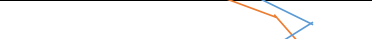 & safety \\
\hline Obvious & & unreasonable \\
\hline Communicative & & restrained \\
\hline Standard & & creative \\
\hline Material & 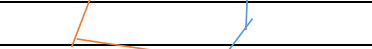 & idea \\
\hline Definite & & indefinite \\
\hline Unexpected & & expected \\
\hline
\end{tabular}


Paper_-Using the Learning Management System "Modular Object-Oriented Dynamic Learning...

\begin{tabular}{|l|c|c|}
\hline Routine & & flexible \\
\hline Motivated & & demotivated \\
\hline Conservative & & innovative \\
\hline Initiative & & passive \\
\hline Clarity & & ambiguity \\
\hline
\end{tabular}

Non-linguistic students

Linguistic students

Table 4. The results of evaluating LMS MOODLE for multilingual education of linguistic and non-linguistic students using a semantic differential method

\begin{tabular}{|c|c|c|c|c|c|c|c|}
\hline \multirow[t]{2}{*}{ No } & \multirow[t]{2}{*}{ Factor scale } & \multicolumn{2}{|c|}{$\begin{array}{c}\text { Group of } \\
\text { respondents }\end{array}$} & \multirow[t]{2}{*}{ Student's t-test } & \multirow[t]{2}{*}{$\mathbf{p}$} & \multirow{2}{*}{$\begin{array}{c}\text { Mann- } \\
\text { Whitney U test }\end{array}$} & \multirow[t]{2}{*}{$\mathbf{p}$} \\
\hline & & $A$ & $B$ & & & & \\
\hline 1. & Positive/negative & 6.08 & 4.50 & 11.17 & $<0.05$ & 405.5 & $>0.05$ \\
\hline 2. & Relevant/irrelevant & 6.41 & 6.10 & 2.19 & $<0.05$ & 330.0 & $>0.05$ \\
\hline 3. & Optimism/pessimism & 6.50 & 5.30 & 8.49 & $<0.05$ & 160.0 & $<0.05$ \\
\hline 4. & Real/unreal & 6.42 & 5.27 & 8.13 & $<0.05$ & 70.0 & $<0.05$ \\
\hline 5. & Easy/complicated & 6.50 & 4.09 & 17.54 & $<0.05$ & 30.0 & $<0.05$ \\
\hline 6. & Important/insignificant & 6.00 & 5.63 & 2.62 & $<0.05$ & 400.0 & $>0.05$ \\
\hline 7. & Far-fetched/reasonable & 6.33 & 6.09 & 1.7 & $>0.05$ & 500.0 & $>0.05$ \\
\hline 8. & Professional/non-professional & 6.41 & 6.27 & 0.99 & $>0.05$ & 560.0 & $>0.05$ \\
\hline 9. & Inconvenient/comfortable & 6.33 & 5.11 & 8.63 & $<0.05$ & 230.5 & $>0.05$ \\
\hline 10. & Proactivity/childishness & 6.56 & 6.33 & 1.63 & $>0.05$ & 310.5 & $>0.05$ \\
\hline 11. & Authoritarian/democratic & 6.67 & 6.56 & 0.78 & $>0.05$ & 360.0 & $>0.05$ \\
\hline 12. & Contemporary/outdated & 6.44 & 6.67 & 1.63 & $>0.05$ & 310.5 & $>0.05$ \\
\hline 13. & Leadership/subordination & 6.33 & 6.11 & 1.56 & $>0.05$ & 340.5 & $>0.05$ \\
\hline 14. & Dependent/solvable & 6.11 & 4.89 & 8.63 & $<0.05$ & 200.0 & $<0.05$ \\
\hline 15. & Help/intervention & 6.67 & 6.22 & 3.18 & $<0.05$ & 220.5 & $>0.05$ \\
\hline 16. & Randomness/stability & 5.56 & 5.33 & 1.63 & $>0.05$ & 350.5 & $>0.05$ \\
\hline 17. & Transparency/secrecy & 6.44 & 5.89 & 3.89 & $<0.05$ & 240.5 & $>0.05$ \\
\hline 18. & Closedness/openness & 6.22 & 5.56 & 4.67 & $<0.05$ & 19.5 & $<0.05$ \\
\hline 19. & Danger/safety & 6.56 & 6.00 & 3.96 & $<0.05$ & 230.0 & $>0.05$ \\
\hline 20. & Obvious/unreasonable & 6.22 & 5.67 & 3.89 & $<0.05$ & 290.5 & $>0.05$ \\
\hline 21. & Communicative/limited & 6.44 & 5.44 & 7.07 & $<0.05$ & 160.0 & $<0.05$ \\
\hline 22. & Standard/Creative & 6.11 & 6.50 & 2.76 & $<0.05$ & 250.5 & $>0.05$ \\
\hline 23. & Material/idea & 6.66 & 6.56 & 0.71 & $>0.05$ & 360.0 & $>0.05$ \\
\hline 24. & Definite/indefinite & 5.89 & 5.56 & 2.33 & $<0.05$ & 310.0 & $>0.05$ \\
\hline 25. & Expected/Unexpected & 5.11 & 4.56 & 3.89 & $<0.05$ & 290.0 & $>0.05$ \\
\hline 26. & Flexible/routine & 5.67 & 5.11 & 3.96 & $<0.05$ & 380.5 & 380.5 \\
\hline 27. & Motivated/Demotivated & 6.56 & 5.56 & 7.07 & $<0.05$ & 270.5 & $>0.05$ \\
\hline 28. & Conservative/innovative & 6.33 & 6.67 & 2.40 & $<0.05$ & 270.0 & $>0.05$ \\
\hline 29. & Proactive/Non-proactive & 6.44 & 6.22 & 1.56 & $>0.05$ & 33.5 & $>0.05$ \\
\hline 30. & Clarity/ambiguity & 6.78 & 5.67 & 7.85 & $<0.05$ & 90.5 & $<0.05$ \\
\hline
\end{tabular}


According to semantic differential method, a number of indicators revealed differences between respondent groups. Language students assessed multilingual education using LMS MOODLE as easier and more comfortable than traditional one. Their indicators statistically significantly differed from those of non-linguistic students, who were less optimistic, less motivated to study, and did not quite clearly imagine future prospects. The factor distribution of the answers of both groups according to semantic differential method is summarized in Figure 1. The average indicators for all three factors have statistically significant differences between the studied groups of students (Table 5).

Table 5. Factor analysis of LMS MOODLE for multilingual education of linguistic and nonlinguistic students

\begin{tabular}{|l|c|c|c|c|c|}
\hline \multirow{2}{*}{ No. } & \multirow{2}{*}{ Factor } & \multicolumn{2}{|c|}{ Group of respondents } & \multirow{2}{*}{ Student's t-test } & \multirow{2}{*}{ p } \\
\cline { 3 - 4 } & & $\boldsymbol{A}$ & $\boldsymbol{B}$ & & $<0.05$ \\
\hline 1. & Assessment & 6.680 & 5.469 & 8.56 & $<0.05$ \\
\hline 2. & Power & 6.322 & 5.878 & 3.14 & $<0.05$ \\
\hline 3. & Activity & 6.199 & 5.785 & 2.93 & \\
\hline \multicolumn{2}{l}{ Correlation coefficient } & 1.000 & 0.625 & & \\
\hline
\end{tabular}

As can be seen from the tabular indicators (Table 5) and clearly shown in Figure 1, despite the fact that both groups of respondents generally gave a positive assessment of the use of LMS MOODLE platform for multilingual education, this assessment among non-linguistic students was low.

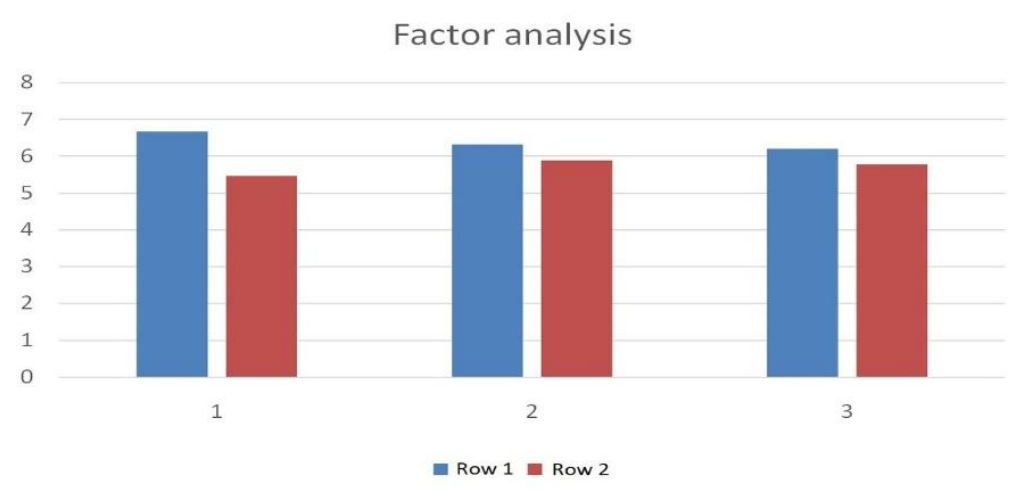

Fig. 1. Comparison of factor analysis indicators of linguistic (row 1) and non-linguistic (row 2) students according to semantic differential method

\section{Discussion}

Recently, more and more scientific publications have covered various aspects of using online technologies in the process of obtaining higher education. The LMS MOODLE platform has become widespread; it is flexible enough to ensure its effec- 
tive use for educational purposes [10,38]. Those specialists who speak foreign languages are competitive in the global labor market; therefore, multilingualism is becoming one of the key students' competencies [5,29]. The combination of two components - multilingualism and online learning - requires a deeper study of this issue in order to optimize the educational process in new conditions.

The present study and other studies [15,18-20] indicate that linguistic universities have a long experience of using distance learning technologies, while many nonlinguistic universities have started online education only due to COVID-19-related quarantine measures. This aspect has led to a number of statistically significant discrepancies in the effectiveness of using LMS MOODLE platform for solving the problems of multilingual education, primarily in the field of motivational, communicative, and emotional-volitional components of multilingual communicative competence [19]. In relation to the influence of LMS MOODLE on the communication of students with teachers, the answers of both groups of respondents were quite comparable and most of them noted an improvement in communication (correlation coefficient 1.000). In relation to classmates, almost half of non-linguistic students noted deterioration in communication, which is twice the number of similar negative answers of the first group of respondents. Greater experience in using LMS MOODLE platform and an interest in multilingual education contribute to more active and effective communication of linguistic students with each other. Non-linguistic students, on the contrary, turn out to be more disunited in this case (correlation coefficient -1.000) since they have different professional interests and the study of foreign languages is not that important for them. However, both groups of respondents unanimously indicated an increase in interest in both learning in general and multilingual education (correlation coefficient 1.000) as a result of using LMS MOODLE platform. Both groups of respondents also noted that this system is convenient (correlation coefficient 1.000) and effective (correlation coefficient 1.000) for solving multilingual learning problems. The majority of students in both study groups indicated that the use of LMS MOODLE platform not only contributed to a significant improvement in foreign language studies (correlation coefficient 1.000) but also improved academic performance (correlation coefficient 1.000). Besides, the overwhelming majority of students indicated the independent work (correlation coefficient 1.000) as the advantage of LMS MOODLE. However, language students predominated statistically $(\mathrm{p}<0.05)$ among those who rated the LMS MOODLE platform as more preferable for multilingual education than traditional classroom work. Non-linguistic students noted the feeling of disunity between classmates in the process of online learning (correlation coefficient 0.500 ). Teachers should pay attention to this when drawing up plans and programs for online classes [2,10]. Unfortunately, many respondents in both study groups (correlation coefficient 1.000) still continue to criticize the possibilities of Internet access and the quality of technical support for online learning. This problem may be associated with both insufficient funding for the technological reequipment of educational institutions and with the lack of qualified IT specialists $[3,6]$. Among the problems and obstacles to the use of LMS MOODLE, the respondents of both groups noted the insufficient readiness of teachers to use ICTs and the lack of students' independent work skills (about half of the surveyed students indicat- 
ed the latter). In addition, a significant number of respondents expressed dissatisfaction with the formal attitude towards the use of LMS MOODLE platform, the lack of feedback or creative assignments from teachers, etc., which directly depend on the level of teachers' qualifications and the motivational component (correlation coefficient 1.000). In this context, it should be noted that the following aspects hinder multilingual education (since in this case, the most important components that contribute to language skills formation are missing):

- lack of external and (or) internal integration between the studied languages;

- learning the native language without any connection to foreign languages;

- lack of connection between the study of foreign languages and other study subjects;

- inconsistency between the educational and research components.

Despite these shortcomings, in general, the use of LMS MOODLE platform for multilingual education received a positive assessment from the respondents of both groups (correlation coefficient 0.975). However, it should be noted that language students more often characterized the results and prospects of using LMS MOODLE for multilingual education as very good, and there were no negative assessments in this group of respondents. The responses of non-language students were more restrained, and several respondents in this group gave LMS MOODLE negative assessment. This point requires more careful consideration, although it can be assumed that negative assessments are associated with insufficient communication with classmates among non-linguistic students and the lack of the necessary independent work skills. Nevertheless, both groups of respondents positively assessed LMS MOODLE in multilingual education for the formation of communicative skills.

One can interpret the research results as a consequence of professional differences since linguistic students initially consciously chose multilingual education as a way to form key professional competence, and LMS MOODLE was seen by them as an effective and convenient means for mastering several foreign languages. They more clearly understand the prospects for using foreign languages in future work. At the same time, some non-linguistic students do not consider mastering foreign languages a key professional competence, do not plan to use foreign languages in their work in the future and thus have a lower level of language proficiency. Accordingly, using the semantic differential method, they were found to have lower indicators of innovativeness and motivation to study in comparison with linguistic students. In addition, the communication factor turned out to be problematic for non-linguistic students, which was revealed using both semantic differential method and questionnaires. Linguistic students have more experience in distance learning, are accustomed to easily and effectively communicate with each other and with teachers using LMS MOODLE. At the same time, non-linguistic students feel a lack of live communication, thus, they are more conservative about the introduction of educational online technologies.

A low assessment of the use of LMS MOODLE platform for multilingual education by non-linguistic students is associated with a lower motivation for learning foreign languages among them as they do not quite understand the importance of this competence for their future profession. At the same time, language students are moti- 
vated to study several foreign languages, linking their professional and career expectations with this competence. In addition, this aspect is not sufficiently taken into account in the policy of non-linguistic educational institutions, which students assess as insufficiently democratic in comparison with language universities. The solution to this problem is seen in the more active work of teachers aimed at improving the adaptation of non-linguistic students to new forms of education for them, as well as developing the communication component of the educational process.

Study limitations were related to the difficulties of conducting it in the context of quarantine restrictions associated with the COVID-19 pandemic. Among the questionnaires, only those were selected in which the respondents answered all questions and indicated that they had experience of active use of LMS MOODLE platform.

\section{Conclusions}

As a result of the study, a significant difference was revealed in the assessment of LMS MOODLE for multilingual education by linguistic and non-linguistic students, which is associated with the difference in the motivation for acquiring multilingual competence and its professional significance. In general, the study results allow one to state that LMS MOODLE is a convenient and promising platform for use in multilingual education of both linguistic and non-linguistic students, which implies its further development and wider application for multilingual education.

Results indicate that linguistic universities have a long experience of using distance learning technologies, while many non-linguistic universities have started online education only due to COVID-19-related quarantine measures. This aspect led to the presence of a number of statistically significant discrepancies in linguistic and nonlinguistic students' assessments of LMS MOODLE effectiveness for multilingual education, mostly, in the field of motivational, communicative, and emotionalvolitional components of multilingual communicative competence.

Experience of using LMS MOODLE and general educational interests in relation to multilingual education contribute to more active and effective communication of linguistic students with each other. Non-linguistic students, on the contrary, turn out to be more disunited since they have different professional interests and the study of foreign languages is not considered by them as a key professional competence, therefore, this factor does not have such a unifying effect for them as for linguistic students. Results suggest that the use of LMS MOODLE stimulates independent work and contributes to a significant improvement of foreign language studies and academic performance of both linguistic and non-linguistic students.

Negative assessments of the use of LMS MOODLE by some non-linguistic students are associated, first of all, with the problems of insufficient communication with classmates, as well as their lack of necessary independent work skills.

The research results have shown the effectiveness and prospects of LMS MOODLE for the simultaneous study of foreign languages and the formation of communicative skills necessary for most specialists in the modern global labor market. However, more active work of teachers is required to improve the adaptation of 
non-linguistic students to new education forms and develop communication component of education. Taking into account the above, the vector of further research should be directed towards studying the ways of forming and developing students' independent work skills and ensuring their effective communication with each other and with teachers in online learning based on the LMS MOODLE platform.

\section{$7 \quad$ Acknowledgment}

Zi-Yu Liu was supported by The Project of Improving the Basic Scientific Research Ability of Young and Middle-aged Teachers in Guangxi Universities: Research on the Improvement of Interpreting Ability based on Cognitive Process in the Age of Technology Empowerment; Project of National Social Sciences Foundation of China (No.19BYY098); University-Industry Collaborative Education Program of Ministry of Education (2020): Research on the Innovative Mode of College English Translation Teaching Based on Autonomous Learning Platform; Research on the Construction of Practical Teaching System for the Cultivation of Applied Talents in Human Resource Management Specialty; Research on the Construction of Crossborder E-commerce Training Base for China-Asean Cooperation.

\section{References}

[1] Sari, R., Sumarmi, S., Astina, I., Utomo, D., Ridhwan, R. (2021). Increasing students critical thinking skills and learning motivation using inquiry mind map. International Journal of Emerging Technologies in Learning, 16(3): 4-19. https://doi.org/10.3991/ijet.v16i03.16 $\underline{515}$

[2] Jebari, K., Boussedra, F., Ettouhami, A. (2017). Teaching "Information Systems Management" with Moodle. International Journal of Emerging Technologies in Learning, 12(4): 4-16. https://doi.org/10.3991/ijet.v12i04.6183

[3] Liu, Z.Y., Lomovtseva, N., Korobeynikova, E. (2020). Online learning platforms: Reconstructing modern higher education. International Journal of Emerging Technologies in Learning, 15(13): 4-21. https://doi.org/10.3991/ijet.v15i13.14645

[4] Zabolotniaia, M., Cheng, Z., Dorozhkin, E., Lyzhin, A. (2020). Use of the LMS Moodle for an effective implementation of an innovative policy in higher educational institutions. International Journal of Emerging Technologies in Learning, 15(13): 172-189. https://doi. org/10.3991/ijet.v15i13.14945

[5] Chicherina, O.V. (2019). Development of scientifically grounded concepts of modernization of the content and technologies of teaching academic subjects. http://conf.apkpro.ru/ doc/.pdf

[6] Mukhametshin, L., Salekhova, L. (2019). Using the LMS Moodle system in the modern educational process. Philology and Culture, 2(56): 274-279. https://doi.org/10.26907/2074 $-0239-2019-56-2-274-279$

[7] Al-Azawei, A., Baiee, W.R., Mohammed, M.A. (2019). Learners' experience towards eassessment tools: A comparative study on virtual reality and Moodle quiz. International Journal of Emerging Technologies in Learning, 14(5): 34-50. https://doi.org/10.3991/ijet. $\underline{\mathrm{v} 14 \mathrm{i} 05.9998}$ 
Paper_-Using the Learning Management System "Modular Object-Oriented Dynamic Learning...

[8] Lui, X. (2018). Impact of computer remote education on CLL learning and solutions. International Journal of Emerging Technologies in Learning, 13(3): 114-128. https://doi.org/ 10.3991/ijet.v13i03.8387

[9] Barbosa, A.F., Rovai, A.A., Concalves, G.K., Miao, F., Domiter, A. (2019). Empowering students to become agents of social transformation through mobile learning in Brazil: case study by the UNESCO-Fazheng project on best practices in mobile learning. Paris: UNESCO.

[10] Cabero-Almenara, J., Arancibia, M.L., Del Prete, A. (2019). Technical and didactic knowledge of the Moodle LMS in higher education: Beyond functional use. Journal of New Approaches in Educational Research, 8(1): 25-33. https://doi.org/10.7821/naer.2019. 1.327

[11] Jorolan-Quintero, G. (2018). Oral traditions: an aid to implementation of mother tonguebased multilingual education in the Philippines' basic education programme. International Review of Education: Journal of Lifelong Learning, 64(6): 759-777. https://doi.org/10.100 7/s11159-018-9743-9

[12] Plyusnina, E.M., Shalgina, E.A., Shustova, S.V. (2017). Formation of multilingual competence. Bulletin of Perm National Research Polytechnic University. Problems of Linguistics and Pedagogy, 2: 121-130. https://doi.org/10.15593/2224-9389/2017.2.12

[13] Malykh, L.M., Zhukova, A.V. (2016). Model of multilingual education in a multi-ethnic region (based on a general educational institution). Izhevsk: Udmurt University.

[14] Kecherukova, M.A. (2016). Creation of a multilingual educational environment. Experience of Tyumen State Oil and Gas University. In XIV International Philological Scientific Conference. St. Petersburg, Russia, pp. 14-21.

[15] Krylov, E.G. (2016). Integrated bilingual teaching of a foreign language and engineering disciplines in a technical university: dissertation for the degree of Dr. of Pedagogy. Yekaterinburg: Perm National Research Polytechnic University.

[16] Obdalova, O.A. (2017). Cognitive-discursive system of teaching foreign language intercultural communication for undergraduate students of natural sciences: dissertation for the degree of Dr. of Pedagogy. Nizhny Novgorod: Nizhny Novgorod Dobrolyubov State Linguistic University.

[17] Tishchenko, Y., Kurkchi, Y. (2019). Multilingual education in multicultural regions: needs, expectations. https://patrir.ro/wp-content/uploads/2019/04/Multilingual-educationin-Ukraine-MLE_report_0615-1.pdf

[18] Milrud, R.P., Maximova, I.R. (2017). Communicative competence: language proficiency or readiness for foreign language communication. Foreign Languages at School, 7: 2-11.

[19] Mosina, M.A., Smirnova, I.V. (2019). Methodology for the formation of intellectual competence of biotechnology students in the process of learning a foreign language. Language and Culture, 46: 236-252. https://doi.org/10.17223/19996195/46/14

[20] Rybkina, S.N. (2015). On some aspects of the implementation of multilingual education in modern universities. Modern Research and Innovation, 3-4: 56-61.

[21] Rybkina, S.N. (2016). About approaches to the creation of textbooks for multilingual education in non-linguistic universities. Modern Scientific Research and Innovations, 9: 403406.

[22] Chiknaverova, K.G. (2016). The concept and methodology for the development of foreign language competence of university students based on enhancing their independence: dissertation for the degree of Dr. of Pedagogy. Nizhny Novgorod: Nizhny Novgorod Dobrolyubov State Linguistic University.

[23] Al-Malah, D.A.R., Hamed, S.I., Alrikabi, H. (2020). The interactive role using the Mozabook digital education application and its effect on enhancing the performance of eLearn- 
Paper-Using the Learning Management System "Modular Object-Oriented Dynamic Learning...

ing. International Journal of Emerging Technologies in Learning, 15(20): 21-41. https:// doi.org/10.3991/ijet.v15i20.17101

[24] Zelenina, T.I., Malykh, L.M. (2009). Multilingual education as an innovation in philology. Foreign Languages in Higher Education, 4(11): 5-13.

[25] Shastina, E.M. (2017). The program of discipline "Theoretical foundations of multilingual education". https://edu.kpfu.ru/pluginfile.php/314471/mod_resource/content/.pdf

[26] Prokhorova, A. (2019). Educational bilingualism as a prerequisite for the development of educational multilingualism. In N. A. Gunina, R. P. Millrood (Eds.), Educational Bilingualism: New Language Pedagogy. Newcastle upon Tyne: Cambridge Scholars Publishing, pp. 73-91.

[27] Prokhorova, A. (2020). Multilingual Communicative Competence of Future Engineers: Essence, Structure, Content. In Integrating Engineering Education and Humanities for Global Intercultural Perspectives. London: Springer Nature, pp. 11-20. https://doi.org/10.1 007/978-3-030-47415-7_2

[28] Prokhorova, A.A., Bezukladnikov, K.E., Zhigalev, B.A., Kruse, B.A. (2018). Features of the formation of a multilingual educational policy in a non-linguistic university. Language and Culture. Tomsk, 42: 163-180. https://doi.org/10.17223/19996195/42/10

[29] Budanova, A.I. (2015). Proficiency in foreign languages as a factor of competitiveness in the domestic labor market. Scientific works: Institute of Economic Forecasting of the Russian Academy of Sciences, 13: 261-175.

[30] Vikulina, M.A., Obdalova, O.A. (2017). Technologies as a way to achieve the goals of foreign language education in higher education. Language and Culture, 38: 171-189. https://doi.org/10.17223/19996195/38/12

[31] Jeljeli, R., Alnaji, L., Khazam, K. (2018). A comparison between Moodle, Facebook, and paper-based assessment tools: Students' perception of preference and effect on performance. International Journal of Emerging Technologies in Learning, 13(5): 86-99. https://doi.org/10.3991/ijet.v13i05.8091

[32] Masterson, M. (2020). An exploration of the potential role of digital technologies for promoting learning in foreign language classrooms: Lessons for a pandemic. International Journal of Emerging Technologies in Learning, 15(14): 83-96. https://doi.org/10.3991/ijet. $\underline{\mathrm{v} 15 \mathrm{i} 14.13297}$

[33] Suartama, K., Setyosari, P., Sulthoni, S., Ulfa, S. (2019). Development of an instructional design model for mobile blended learning in higher education. International Journal of Emerging Technologies in Learning, 14(16): 4-22. https://doi.org/10.3991/ijet.v14i16.106 $\underline{33}$

[34] Tleubay, S., Nurzhanova, G., Ybyshova, S., Abdigulova, S., Mankesh, A., Kerimbekov, T., Ualikhanuly, A. (2020). The formation of intercultural communicative competence of future teachers in a trilingual educational environment. International Journal of Emerging Technologies in Learning, 15(17): 148-164. https://doi.org/10.3991/ijet.v15i17.14249

[35] Alkhattabi, M. (2017). Augmented reality as e-learning tool in primary schools' education: Barriers to teachers' adoption. International Journal of Emerging Technologies in Learning, 12(2): 91-100. https://doi.org/10.3991/ijet.v12i02.6158

[36] Chootongchai, S., Songkram, N. (2018). Design and development of SECI and Moodle online learning systems to enhance thinking and innovation skills for higher education learners. International Journal of Emerging Technologies in Learning, 13(3): 154-172. https://doi.org/10.3991/ijet.v13i03.7991

[37] Zhang, Y., Ghandour, A., Shestak, V. (2020). Using learning analytics to predict students performance in Moodle LMS. International Journal of Emerging Technologies in Learning, 15(20): 102-115. https://doi.org/10.3991/ijet.v15i20.15915 
Paper-Using the Learning Management System "Modular Object-Oriented Dynamic Learning...

[38] Aikina, T.Y., Bolsunovskaya, L.M. (2020). Moodle-based learning: Motivating and demotivating factors. International Journal of Emerging Technologies in Learning, 15(2): 239248. https://doi.org/10.3991/ijet.v15i02.11297

[39] Bovina, I. (2006). Semantic differential. In T.V. Folomeeva (Ed.), Social psychology. Workshop, Moscow: Aspect press, pp. 90-104.

[40] Sikevich, Z.V. (2016). The method of semantic differential in sociological research (experience of application). Bulletin of St. Petersburg University, 12(3): 118-128. https://doi.org $\underline{/ 10.21638 / 11701 / \mathrm{spbu} 12.2016 .309}$

\section{$9 \quad$ Authors}

Si Qin is with HuBei University of Economics, Hubei, China.

Larisa Orchakova is with Moscow City University, Moscow, Russia.

Zi-Yu Liu is with GuangXi Normal University, Guilin, China.

Yulia Smirnova is with Moscow City University, Moscow, Russian Federation.

Elena Tokareva is with Moscow City University, Moscow, Russian Federation.

Article submitted 2021-07-30. Resubmitted 2021-11-08. Final acceptance 2021-11-08. Final version published as submitted by the authors. 